\title{
Thermal analysis, X-ray diffraction, spectroscopy studies and magnetic properties of the new compound $\mathrm{Tl}_{2} \mathrm{HAsO}_{4} \cdot \mathrm{Te}(\mathrm{OH})_{6}$.
}

I. Bechibani ${ }^{1}$, H. litaiem ${ }^{1 \star}$, S. Garcia-Granda ${ }^{2}$, M. Dammak ${ }^{1}$, L. Ktari ${ }^{1}$.

${ }^{1}$ Inorganic Chemistry Laboratory, University of Sfax, Faculty of Sciences of Sfax, Tunisia.

E-mail address: ikrambechibani@yahoo.fr; litaiemh@yahoo.fr; meddammak@yahoo.fr; ktarililia@yahoo.fr;

${ }^{2}$ Physical and Analytical Chemistry Laboratory, Faculty of Chemistry, University of Oviedo, Spain.

E-mail address: sgg@uniovi.es

\section{ABSTRACT:}

The $\mathrm{Tl}_{2} \mathrm{HAsO}_{4}$. $\mathrm{Te}(\mathrm{OH})_{6}(\mathrm{TIAsTe})$ compound crystallizes in the triclinic system $\mathrm{P} 1$ with unit cell parameters: $\mathrm{a}=7.100(10) \AA$, $b=7.281(13) \AA, c=8.383(11) \AA, \alpha=76.91(1)^{\circ}, \beta=87.16(1)^{\circ}, \gamma=66.96(2)^{\circ}, Z=2$ and $V=388.19(1) \AA^{3}$. This new structure can be described as a lamellar one with the atomic arrangement being built by planes of $\mathrm{Te}(\mathrm{OH})_{6}$ octahedra alterning with planes of arsenate tetrahedra. Raman and infrared spectra recorded at room temperature confirm the presence of $\mathrm{AsO}_{4}^{3-}$ and $\mathrm{TeO}_{6}^{6-}$ groups and characterize the hydrogen bonds present in the crystal lattice. Differential scanning calorimerty (DSC) shows the presence of three-phase transitions at $396 \mathrm{~K}, 408 \mathrm{~K}$ and $430 \mathrm{~K}$ present in the title compound. Typical thermal analyses, such as differential thermal analysis (DTA) and thermogravimetry (TG-DTG) show that the decomposition of this material starts at about $\mathrm{T}=445 \mathrm{~K}$. Magnetization curve of $\mathrm{Tl}_{2} \mathrm{HAsO} \mathrm{O}_{4} \cdot \mathrm{Te}(\mathrm{OH})_{6}$ substance have revealed a diamagnetic response overall temperature range studied.

Keywords: X ray-diffraction; IR; Raman; DSC; Crystal structure.

*Corresponding Author Tel: +(216)22371409

E-mail address: litaiemh@yahoo.fr

\section{Council for Innovative Research}

Peer Review Research Publishing System

\section{Journal: Journal of Advances in Chemistry}

Vol. 7, No. 3

editor@cirworld.com

www.cirjac.com, member.cirworld.com 


\section{INTRODUCTION:}

A large number of telluric salts with general formula $M_{2} A O_{4} \cdot T e(O H)_{6}$, where $M$ is a monovalent cations and $(A=A s, S$, Se...), undergo several structural phase transitions and interesting physical properties [1-6]. In order to expand upon the emergent chemistry of template tellurate a new compound using the arsenate group $\mathrm{HAsO}_{4}^{2-}$ has been synthesized. Thus, the presence of the hydrogen atom in this ionic group can differentiate this new tellurate to other previously studied and give new insights on the addition compound based on tellurate. Therefore, there is a great interest to create and study the new family of arsenates tellurates.

In this paper, we present and discuss the results of our investigation concerning the (TIAsTe) material by X-ray diffraction, IR and Raman studies, thermal analysis (DSC, DTA, DTG and TG) and magnetic properties.

\section{EXPERIMENTAL:}

Colorless and transparent single crystals of $\mathrm{Tl}_{2} \mathrm{HAsO}_{4} \cdot \mathrm{Te}(\mathrm{OH})_{6}$ were prepared by slow evaporation at room temperature from a mixture solution of telluric acid $\mathrm{H}_{6} \mathrm{TeO}_{6}$, thallium carbonate $\mathrm{Tl}_{2} \mathrm{CO}_{3}$ and arsenic acid $\mathrm{H}_{3} \mathrm{AsO}_{4}$ in the stoechiometric ratio reaction.

$\mathrm{Tl}_{2} \mathrm{CO}_{3}+\mathrm{H}_{3} \mathrm{AsO}_{4}+\mathrm{H}_{6} \mathrm{TeO}_{6}$

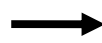

$\mathrm{Tl}_{2} \mathrm{HAsO}_{4} \cdot \mathrm{Te}(\mathrm{OH})_{6}+\mathrm{H}_{2} \mathrm{O}+\mathrm{CO}_{2}$

The formula of this material was determined by chemical analysis and confirmed by structural refinement. The structure was solved by using the SUPERFLIP program [7] and completed by the Fourier synthesis performed using SHELXL-97 program [8]. The structure graphics were created by the Diamond program [9]. The masses of samples used in TG, DTG and DTA measurements were $9.035 \mathrm{mg}$. Differential scanning calorimetry (DSC) measurements were carried out by means of a Mettler Toledo DSC model DSC821 with samples placed inside platinum crucibles, at a heating rate of $5 \mathrm{~K} / \mathrm{min}$.

Infrared absorption spectra of suspension of crystalline in $\mathrm{KBr}$ have been recorded using Jasco-FT-IR-420 spectrophotometer in the $(4000-500) \mathrm{cm}^{-1}$ frequency range. Raman spectra of polycrystalline samples sealed in glass tubes have been recorded on a Labrama HR 800 instrument using $632.81 \mathrm{~nm}$ radiations from a physics argon ion laser.

The details of data collection and refinement for the title compound are summarized in Table 1. The final positions and equivalent isotropic atomic displacement parameters for the new compound are given in Table 2 and Table 3.

\section{RESULTS AND DISCUSSION:}

\subsection{Calorimetric study:}

A typical result of the calorimetric study of the $\mathrm{Tl}_{2} \mathrm{HAsO}_{4} \cdot \mathrm{Te}(\mathrm{OH})_{6}$ compound is presented in Figure 1. The superposition of TG-DTA and DTG curves are showing in Figure 2. According to these figures, the (TIAsTe) material presents three-phase transitions at $T=408 \mathrm{~K}$, with a shoulder at $\mathrm{T}=396 \mathrm{~K}$, and an endothermic peak at $\mathrm{T}=430 \mathrm{~K}$, also we can deduce that the decomposition of this material starts at about $\mathrm{T}=445 \mathrm{~K}$. In fact, the first mass loss of $4.5 \%$ may be corresponding to the release of two water molecules per chemical formula. Thus, in the temperature range $400 \mathrm{~K}-500 \mathrm{~K}$ the telluric acid $\mathrm{Te}(\mathrm{OH})_{6}$ decomposes to disengage the water molecule and give the orthotelluric acid $\mathrm{H}_{2} \mathrm{TeO}_{4}[6,30]$.

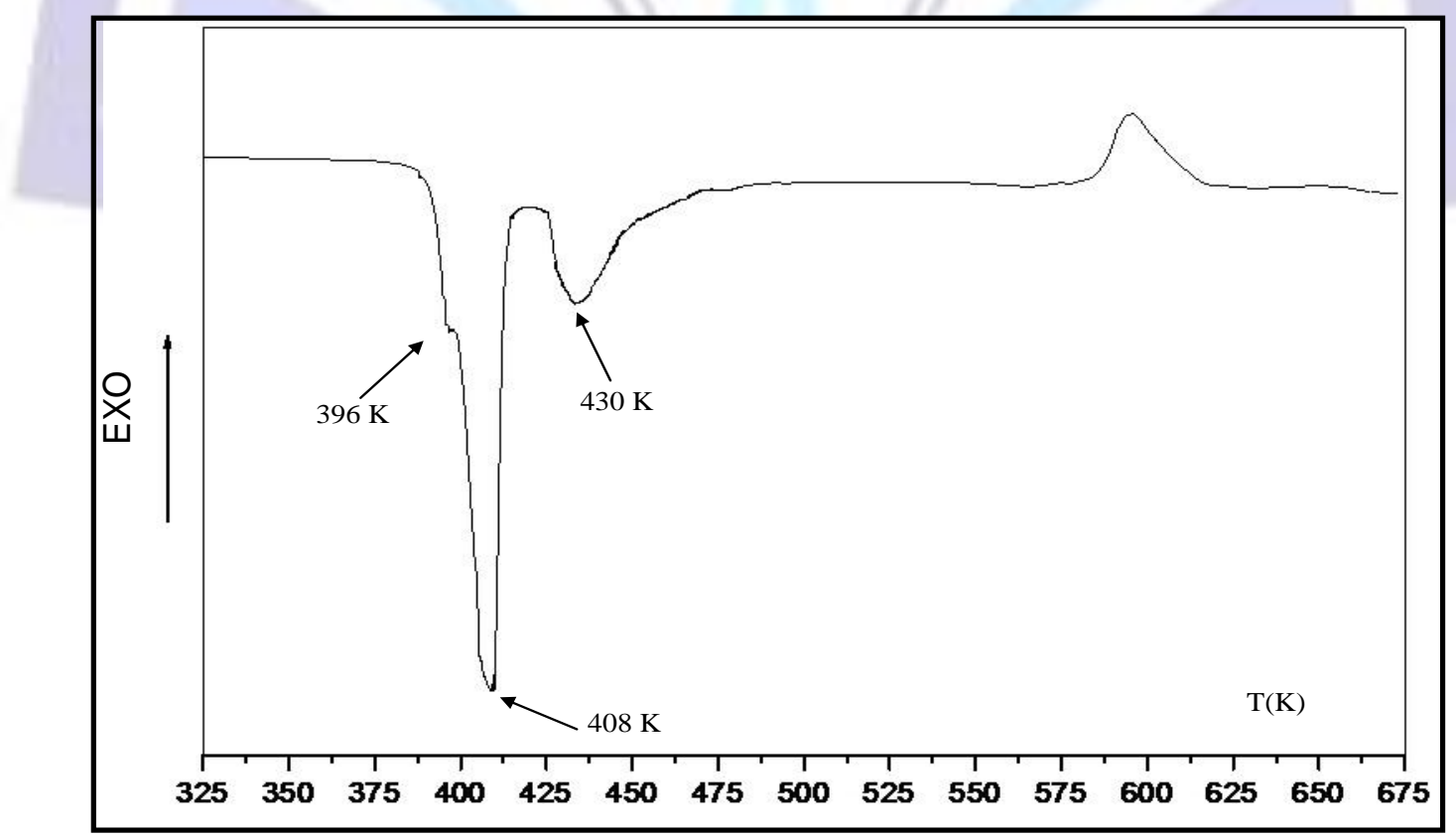

Fig 1. DSC heating curve of $\mathrm{Tl}_{2} \mathrm{HAsO}_{4} . \mathrm{Te}(\mathrm{OH})_{6}$ material. 
By comparison with the $\mathrm{Tl}_{2} \mathrm{SeO}_{4} \mathrm{Te}(\mathrm{OH})_{6}$ (TISeTe) material that exhibits three endothermic peaks at 373,395 and 437 $\mathrm{K}$. The first peak at $373 \mathrm{~K}$ was attributed to a structural phase transition. Whereas, the second peak, at about $395 \mathrm{~K}$, was assimilated to a ferroelectric paraelectric phase transition. The third peak detected at $437 \mathrm{~K}$ was assigned to ionic protonic conduction type [10]. We can estimate that the first and the second peaks can be assimilated to an orderdisorder phase transitions. The third peak detected at $\mathrm{T}=430 \mathrm{~K}$ may be of ionic protonic conduction type. The calculated transition enthalpies, for the first transition at $T_{1}=408 \mathrm{~K}$ and for the third anomaly at $T_{3}=430 \mathrm{~K}$ are respectively $\Delta \mathrm{H}_{1}=937.26 \mathrm{Jg}^{-1}$ and $\Delta \mathrm{H}_{3}=400.38 \mathrm{Jg}^{-1}[1,2,10]$.

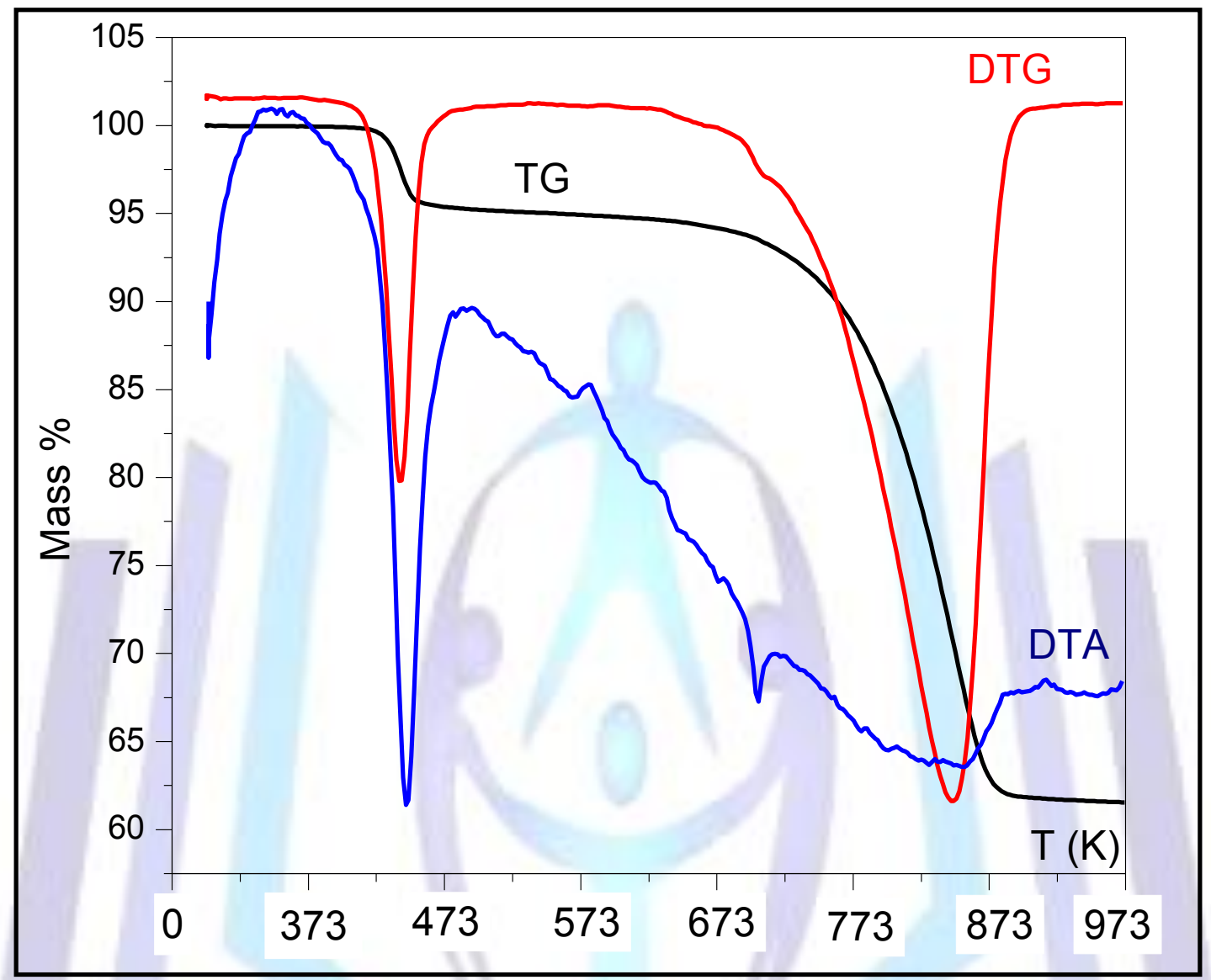

Fig 2. TG-DTA, and DTG heating curve of $\mathrm{Tl}_{2} \mathrm{HAsO}_{4} \cdot \mathrm{Te}(\mathrm{OH})_{6}$ compound.

\subsection{Structural study:}

At room temperature, the structure of (TIAsTe) is triclinic with unit cell parameters are $a=7.100(10) \AA, b=7.281(13) \AA$, $\mathbf{c}=$ 8.383(11) $\AA, \alpha=76.91(1)^{\circ}, \beta=87,16(1)^{\circ}, Y=66.96(2)^{\circ}, Z=2$ and $V=388.19(1) \AA^{3}$. While the (TISeTe) crystallizes in the monoclinic system $P 2{ }_{1} / c$ with unit cell parameters are $a=12.358(3) \AA, b=7.231(1) \AA, c=11.986(2) \AA, \beta=111.09(2)^{\circ}, Z=4$ and $V=999.6(4) \AA^{3}[10]$. The volume of the asymmetric unit for the (TISeTe) is slightly higher due to the differences on anion sizes. The projections of the (TIAsTe) on the ab and ac planes (Figure 3 and Figure 4) show that the structure seems to be a lamellar one. In fact, we observe two $\mathrm{AsO}_{4}$ tetrahedra layers and one $\mathrm{TeO}_{6}$ octahedra layer, alterning with $\mathrm{TI}^{+}$cations, connected by $\mathrm{O}-\mathrm{H}$... O hydrogen bonds. Besides, we can describe our structure as chain of planes of differents polyhedra linked by $\mathrm{O}-\mathrm{H} . . . \mathrm{O}$ hydrogen bond and planes of $\mathrm{Tl}^{+}$cations. The sets of these planes are connected by eloctrostatic actions of the $\mathrm{TI}^{+}$cations as shown in Figure 4 and Figure 5. 
Table 1. Main crystallographic features X-ray diffraction parameters of $\mathrm{Tl}_{2} \mathrm{HAsO}_{4} \cdot \mathrm{Te}(\mathrm{OH})_{6}$.

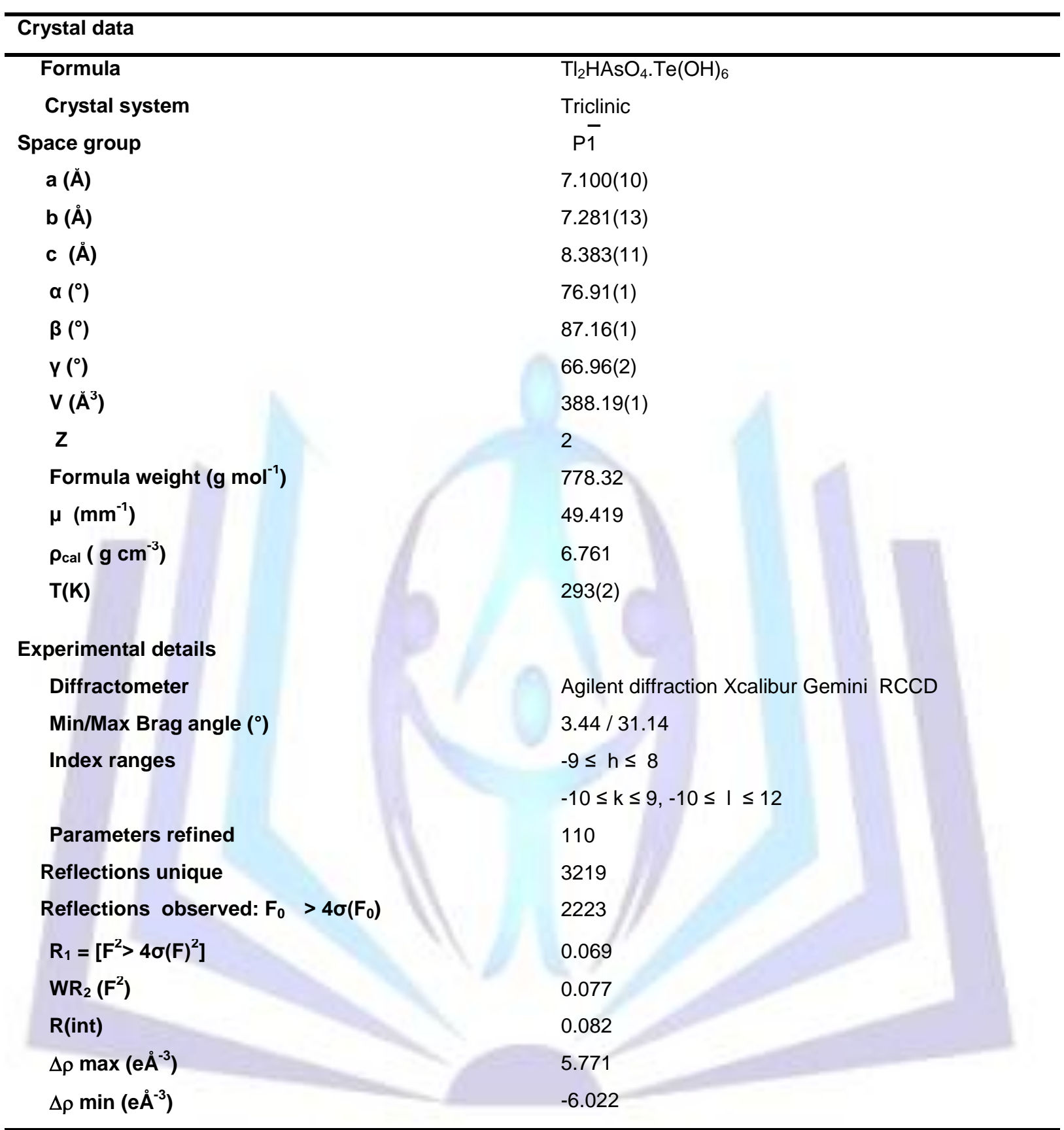


Table 2. Fractional atomic coordinates and equivalent isotropic displacement parameters ( $\mathrm{U}_{\text {iso }}$ for $\mathrm{H}$ atoms) for $\mathrm{Tl}_{2} \mathrm{HAsO}_{4}$. $\mathrm{Te}(\mathrm{OH})_{6}$.

\begin{tabular}{|c|c|c|c|c|}
\hline Atoms & $\bar{X}$ & $\mathbf{Y}$ & $\mathbf{Z}$ & $U_{\text {iso /équiv }}$ \\
\hline $\mathrm{TI}_{1}$ & $0.397(11)$ & $0.262(11)$ & $0.011(9)$ & $0.024(3)$ \\
\hline $\mathrm{TI}_{2}$ & $0.847(11)$ & $0.385(12)$ & $0.373(9)$ & $0.027(3)$ \\
\hline $\mathrm{Te}$ & 0.500 & 0.000 & 0.500 & $0.010(3)$ \\
\hline As & $0.162(2)$ & $0.714(2)$ & $0.174(18)$ & $0.011(4)$ \\
\hline $\mathrm{O}_{1}$ & $0.458(2)$ & $0.275(18)$ & $0.495(15)$ & $0.018(2)$ \\
\hline $\mathrm{O}_{2}$ & $0.642(2)$ & $0.010(19)$ & $0.299(16)$ & $0.021(3)$ \\
\hline $\mathrm{O}_{3}$ & $0.248(2)$ & $0.102(19)$ & $0.374(16)$ & $0.019(2)$ \\
\hline $\mathrm{O}_{21}$ & $0.200(2)$ & $0.929(2)$ & $0.148(17)$ & $0.026(3)$ \\
\hline $\mathrm{O}_{22}$ & $0.386(18)$ & $0.508(18)$ & $0.198(17)$ & $0.021(3)$ \\
\hline $\mathrm{O}_{23}$ & $0.004(2)$ & $0.686(2)$ & $0.324(16)$ & $0.027(3)$ \\
\hline $\mathrm{O}_{24}$ & $0.057(2)$ & $0.714(2)$ & $-0.011(17)$ & $0.025(3)$ \\
\hline $\mathrm{H}_{1}$ & $0.40(4)$ & $0.37(3)$ & $0.44(3)$ & 0.050 \\
\hline $\mathrm{H}_{2}$ & $0.71(4)$ & $0.05(5)$ & $0.22(3)$ & 0.050 \\
\hline $\mathrm{H}_{3}$ & $0.25(5)$ & $0.05(5)$ & $0.30(3)$ & 0.050 \\
\hline $\mathrm{H}_{24}$ & $-0.03(4)$ & $0.82(3)$ & $-0.04(4)$ & 0.050 \\
\hline
\end{tabular}

Table 3. Anisotropic displacement parameters of $\mathrm{Tl}_{2} \mathrm{HAsO}_{4} \cdot \mathrm{Te}(\mathrm{OH})_{6}$ compound

\begin{tabular}{lllllll}
\hline Atoms & $\mathbf{U}_{11}$ & $\mathbf{U}_{22}$ & $\mathbf{U}_{33}$ & $\mathbf{U}_{23}$ & $\mathbf{U}_{13}$ & $\mathbf{U}_{12}$ \\
\hline $\mathrm{TI}_{1}$ & $0.0222(4)$ & $0.0233(4)$ & $0.0288(4)$ & $-0.0084(3)$ & $0.0027(3)$ & $-0.0070(3)$ \\
$\mathrm{TI}_{\mathbf{2}}$ & $0.0222(4)$ & $0.0334(5)$ & $0.0232(4)$ & $-0.006(3)$ & $0.0007(3)$ & $-0.0065(3)$ \\
$\mathbf{T e}$ & $0.0088(6)$ & $0.0075(6)$ & $0.0084(6)$ & $0.0031(4)$ & $-0.0024(4)$ & $0.0007(4)$ \\
$\mathbf{A s}$ & $0.0104(7)$ & $0.0080(6)$ & $0.0101(7)$ & $0.0006(5)$ & $-0.0004(5)$ & $0.0010(5)$ \\
$\mathbf{O}_{1}$ & $0.027(6)$ & $0.007(5)$ & $0.014(5)$ & $-0.001(4)$ & $-0.003(5)$ & $-0.001(4)$ \\
$\mathbf{O}_{2}$ & $0.019(6)$ & $0.013(5)$ & $0.018(6)$ & $0.003(4)$ & $0.009(5)$ & $0.002(4)$ \\
$\mathbf{O}_{3}$ & $0.022(6)$ & $0.015(5)$ & $0.021(6)$ & $-0.002(4)$ & $-0.008(5)$ & $-0.010(5)$ \\
$\mathbf{O}_{21}$ & $0.027(7)$ & $0.026(7)$ & $0.024(7)$ & $-0.009(6)$ & $-0.010(5)$ & $-0.005(5)$ \\
$\mathbf{O}_{22}$ & $0.012(5)$ & $0.010(5)$ & $0.030(7)$ & $0.005(4)$ & $-0.006(5)$ & $0.003(5)$ \\
$\mathbf{O}_{23}$ & $0.022(6)$ & $0.025(6)$ & $0.018(6)$ & $0.004(5)$ & $0.009(5)$ & $-0.001(5)$ \\
$\mathbf{O}_{24}$ & $0.036(8)$ & $0.020(6)$ & $0.020(6)$ & $-0.010(6)$ & $-0.007(5)$ & $-0.004(5)$
\end{tabular}

The anisotropic displacement exponent takes the form: $\operatorname{Exp}\left[-2 \pi^{2} \sum_{i} \sum_{j} U_{i j} h_{i} h_{j} a_{i} a_{j}^{*}\right]$. 


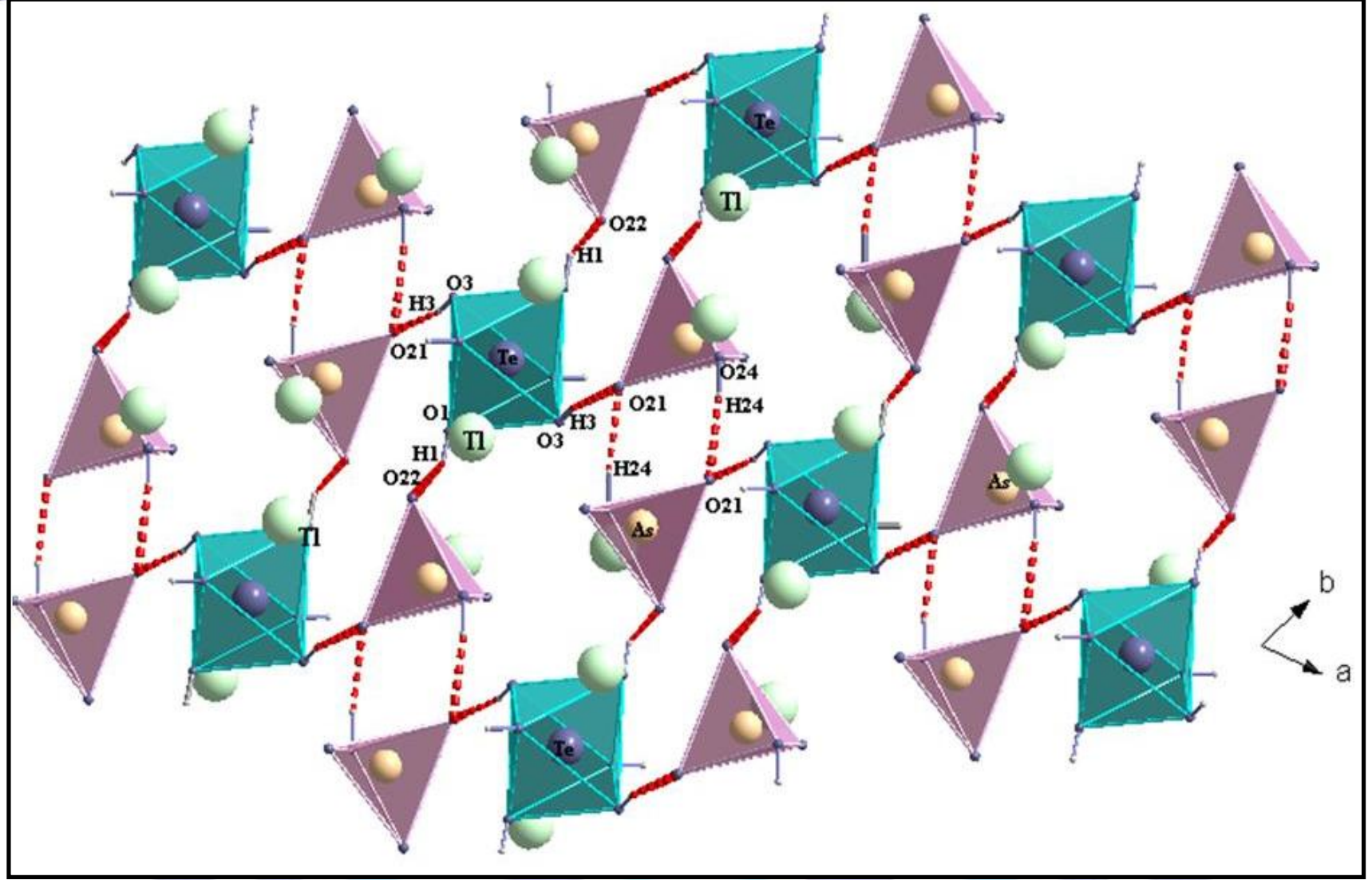

Fig 3: Hydrogen bonds in $\mathrm{Tl}_{2} \mathrm{HAsO}_{4} . \mathrm{Te}(\mathrm{OH})_{6}$ material.

The Te atom in the (TIAsTe) structure occupies a general position, with Te-O bond length varies between 1.900(12) $\AA$ and $1.918(12) \AA$, forming angles values range from $88.17(5)^{\circ}$ to $91.83(5)^{\circ}$. Whilst in the cubic system $\mathrm{F} 4{ }_{1} 32$, the $\mathrm{Te}(\mathrm{OH})_{6}$ structure shows Te-O bond length equal to $1.917 \AA$ with the O-Te-O angles varying from $88.3(1)^{\circ}$ to $93.6(1)^{\circ}[11]$. In the $\mathrm{Tl}_{2} \mathrm{SeO}_{4} \cdot \mathrm{Te}(\mathrm{OH})_{6}$, the Te-O bond length raging from 1.892(6) $\AA$ to $1.937(3) \AA$, the O-Te-O varies from $87.3(3)^{\circ}$ to $92.7(7)^{\circ}$ [10]. Whereas in the $\mathrm{Tl}_{2} \mathrm{SO}_{4} \cdot \mathrm{Te}(\mathrm{OH})_{6}$ structure, the Te-O bond lengths are between 1.912(6) $\AA$ and 1.941(6) $\AA$, the O-Te-O ranging from $87.9(4)^{\circ}$ to $94.1(4)^{\circ}$ [12]. The structural result shows that the $\mathrm{TeO}_{6}$ octahedra, in this new structure, is more regular than those found in $\mathrm{Tl}_{2} \mathrm{SeO}_{4} \cdot \mathrm{Te}(\mathrm{OH})_{6}$ and $\mathrm{Tl}_{2} \mathrm{SO}_{4} \cdot \mathrm{Te}(\mathrm{OH})_{6}$ structures.

In the tetrahedral group, the As-O distances vary from 1.674(14) $\AA$ to $1.751(14) \AA$. The O-As-O angles are between $103.61(7)^{\circ}$ and $113.00(7)^{\circ}$. From these values, we can observe an important deformation of these groups compared with those in the $\mathrm{Rb}_{2} \mathrm{HAsO}_{4}$. $\mathrm{Te}(\mathrm{OH})_{6}$ where As-O distances are between 1.661(14) $\AA$ and 1.725(15) $\AA$, and the O-As-O angles are between $104.69(7)^{\circ}$ and $113.72(8)^{\circ}$ [6]. The deformation may be due to the difference between the cations bulk. Whereas, in the $\mathrm{H}_{3} \mathrm{AsO}_{4}$ the bond length As-O varying from $1.66 \AA$ to $1.71 \AA$ [13]. 


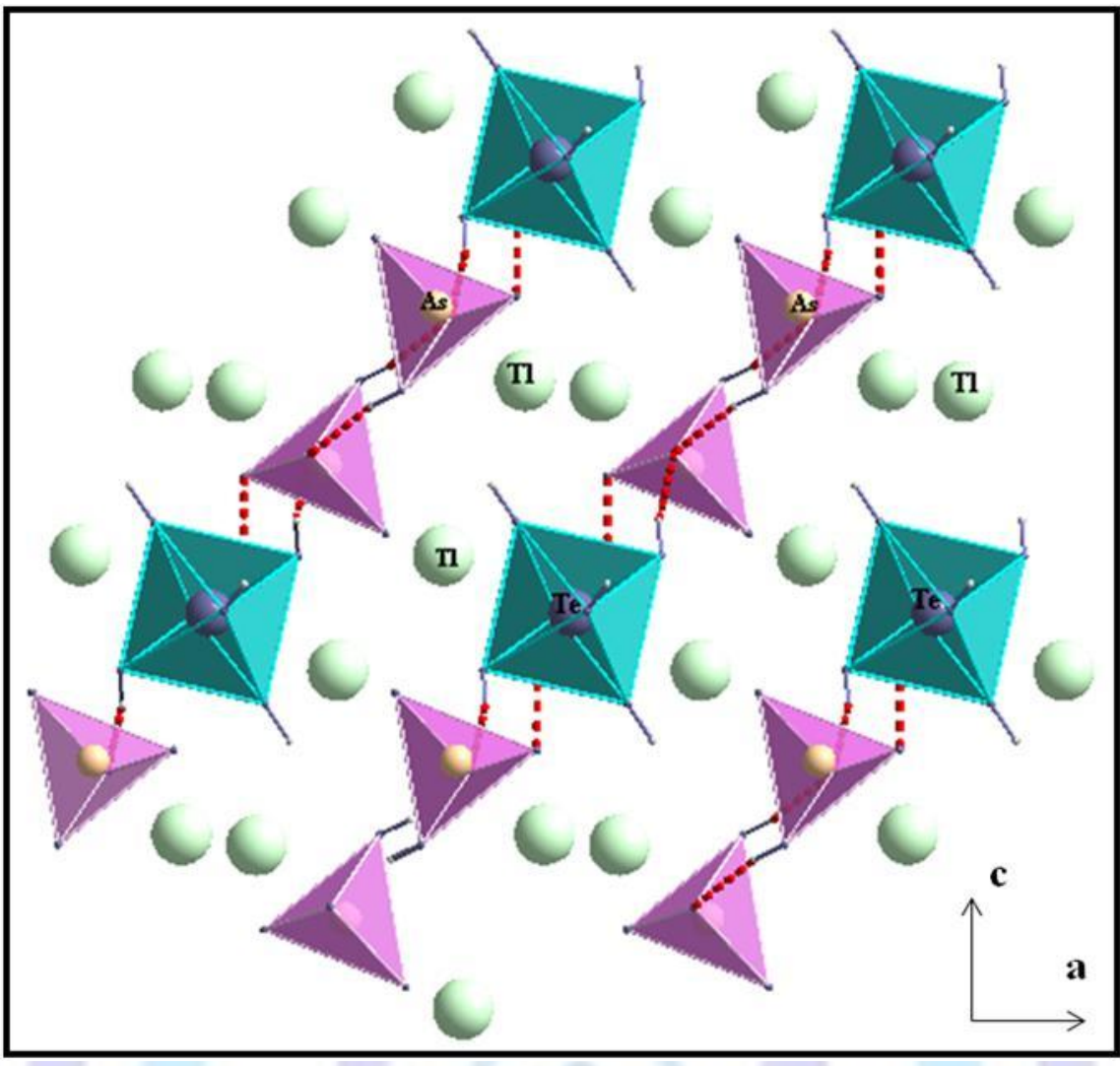

Fig 4: Arrangement of polyhedra layers of $\mathrm{Tl}_{2} \mathrm{HAsO}_{4} \cdot \mathrm{Te}(\mathrm{OH})_{6}$ in the ac plane.

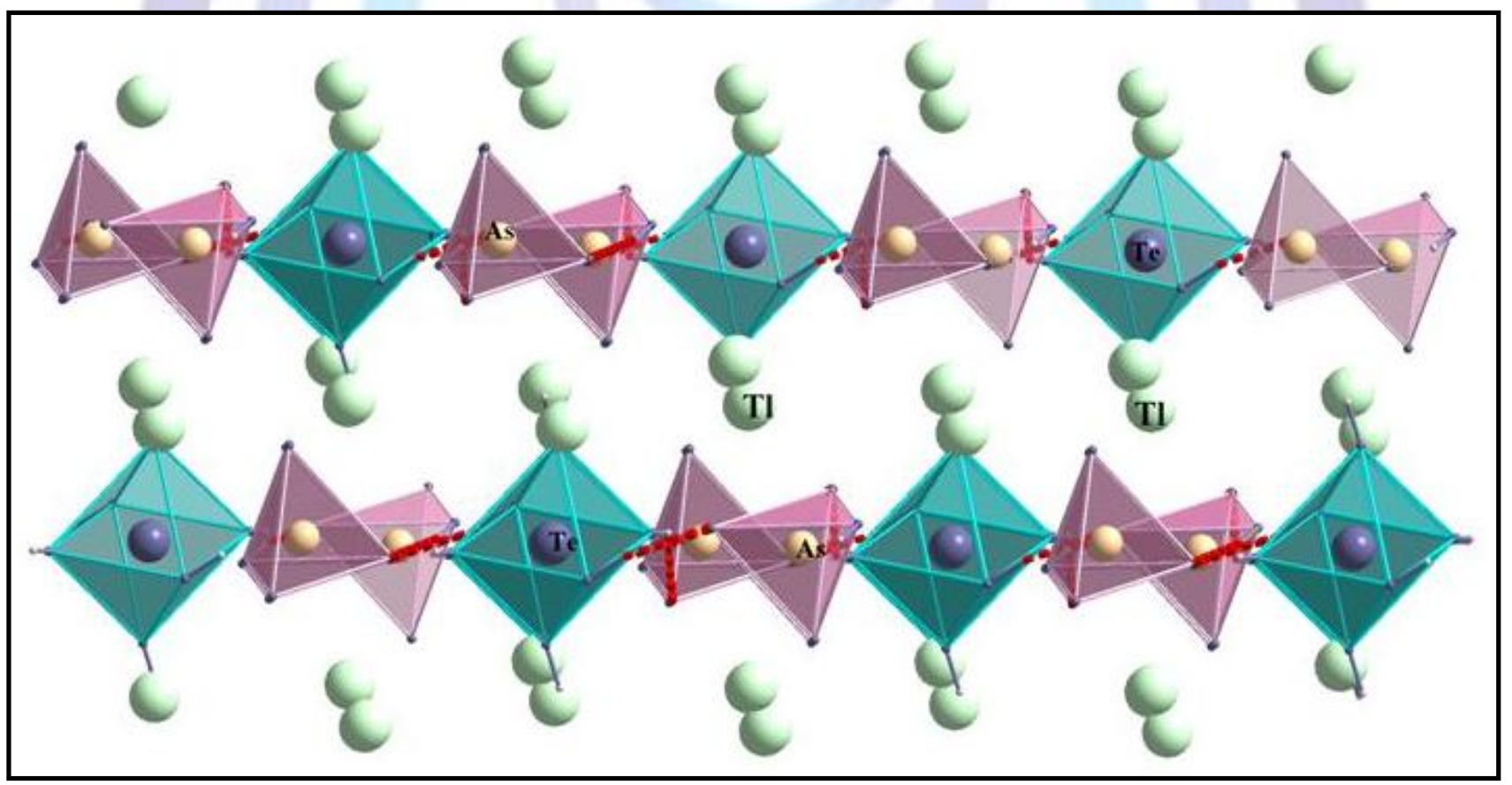

Fig 5: Arrangement of polyhedra planes and cations planes in the $\mathrm{Tl}_{2} \mathrm{HAsO}_{4} \cdot \mathrm{Te}(\mathrm{OH})_{6}$ material.

In (TIAsTe) structure the $\mathrm{TI}^{+}$cations occupies two independent positions. According to Figure 6 both $\mathrm{TI}^{+}$cations are coordinated by eight oxygen atoms similarly to those in $\mathrm{Tl}_{2} \mathrm{SeO}_{4} \cdot \mathrm{Te}(\mathrm{OH})_{6}$ structure. The $\mathrm{TlO}_{8}$ dodecahedra are considerably distorted, being the TI-O distances ranging between $2.603(18) \AA$ and 3.734(15) $\AA$. The bond lengths and the bond angles are listed in Table 4. 
Table 4. Main inter atomic distances $\left(\stackrel{\AA}{)}\right.$ and bond angles $\left(^{\circ}\right)$ in the $\mathrm{Tl}_{2} \mathrm{HAsO} \mathrm{O}_{4} \cdot \mathrm{Te}(\mathrm{OH})_{6}$ material.

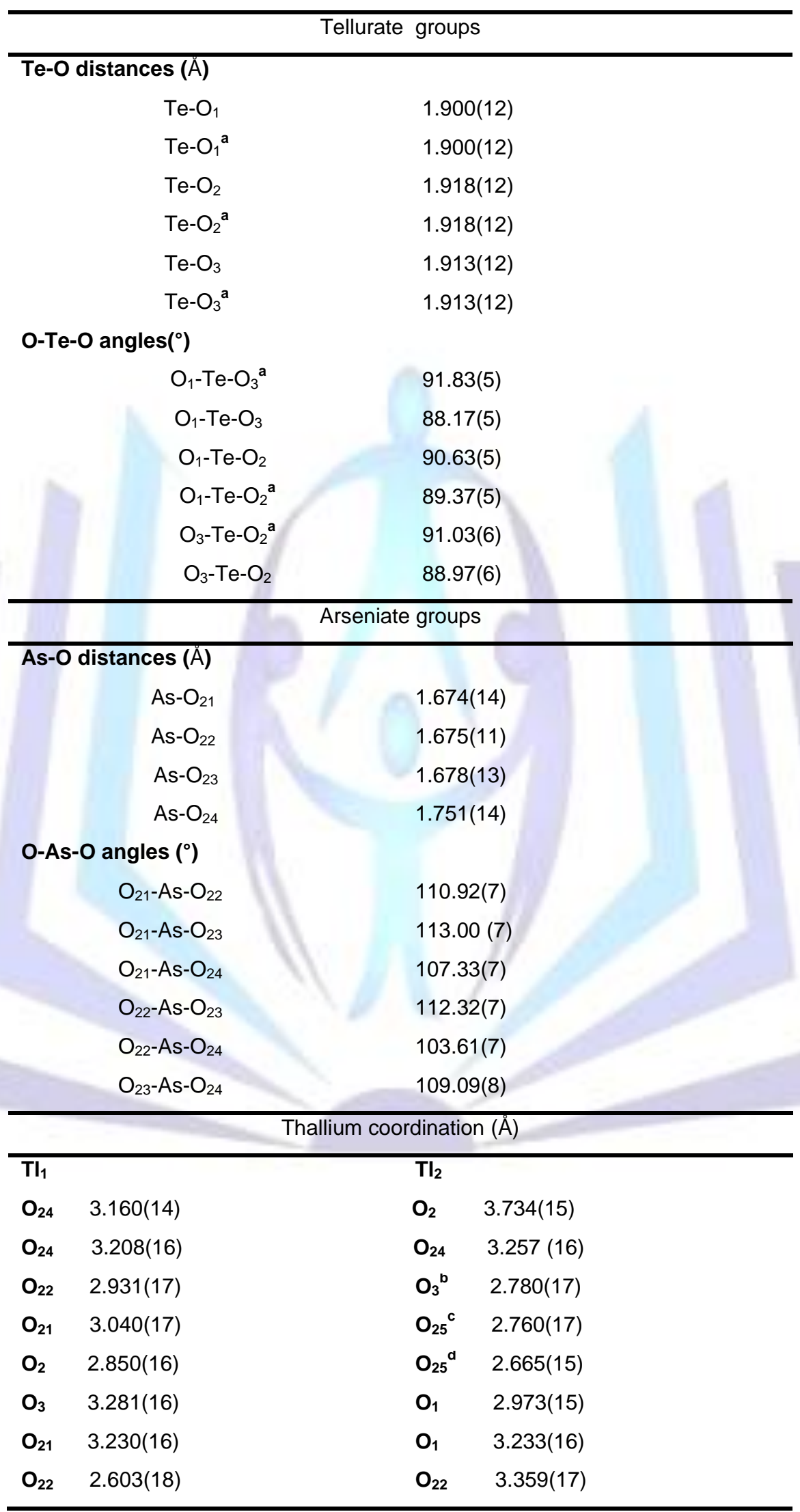

Symmetry code : (a) $-x+1,-y,-z+1$; (b) $x-1, y, z ;$ (c) $x+1, y, z ;$ (d) $-x+1,-y+1,-z+1$. 


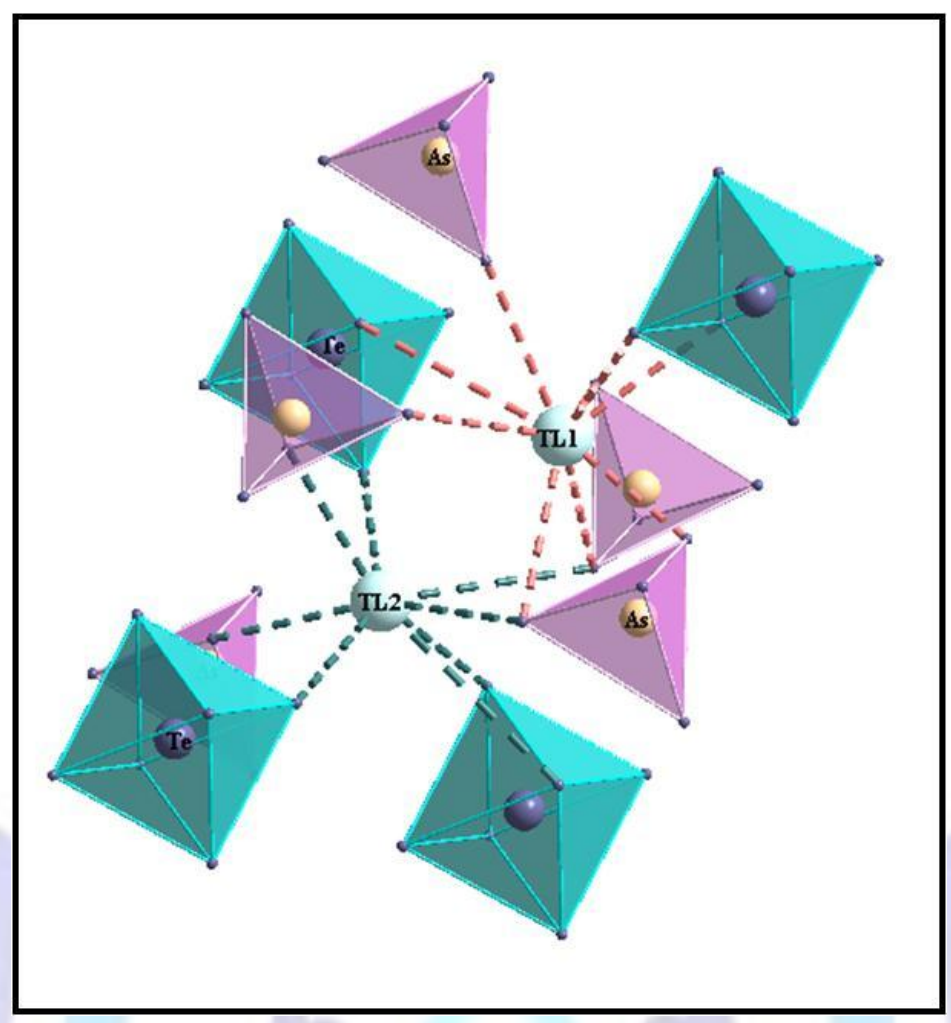

Fig 6: Thallium coordination.

The $\mathrm{Tl}_{2} \mathrm{HAsO}_{4} \cdot \mathrm{Te}(\mathrm{OH})_{6}$ structure is stabilized thanks to hydrogen bonds assured by protons belonging to hydroxide groups linked on the one hand the octahedra on tetrahedra groups. On the other hand, they assured the connectivity between the nearest tetrahedra with $\mathrm{O}_{24}-\mathrm{H}_{24} \ldots \mathrm{O}_{21}$ hydrogen bond. According to Figure 3 and Figure 4, we can deduce that the (TIAsTe) structure is a succession of two planes of tetrahedra then one plane of octahedral linked with strong $\mathrm{O}$ $\mathrm{H}$...O hydrogen bond related to the Brown theory [14]. In fact, the O...O bonds varying from $2.561 \AA$ to $2.623 \AA$. The O$\mathrm{H}$...O angles ranging from $141.10^{\circ}$ to $170^{\circ}$. These values are different to those found in $\mathrm{Rb}_{2} \mathrm{HAsO}_{4} \cdot \mathrm{Te}(\mathrm{OH})_{6} \mathrm{material}$ where the $\mathrm{O} \ldots \mathrm{O}$ bonds range from $2.471 \AA$ to $2.685 \AA$. The $\mathrm{O}-\mathrm{H} \ldots \mathrm{O}$ angles are between $114.32^{\circ}[6]$ and $170.17^{\circ}$.

Table 5. Geometrical characterization of hydrogen bonds in the $\mathrm{Tl}_{2} \mathrm{HAsO}_{4} \cdot \mathrm{Te}(\mathrm{OH})_{6}$ compound.

\begin{tabular}{clll}
\hline $\mathbf{O} \ldots \mathbf{O}(\dot{\mathbf{A}})$ & $\mathbf{O}-\mathbf{H}(\dot{\mathbf{A}})$ & $\mathbf{O} \ldots \mathbf{H}(\dot{\mathbf{A}})$ & $\mathbf{O}-\mathbf{H} \ldots \mathbf{O}\left(^{\circ}\right)$ \\
\hline $\mathrm{O}_{24} \ldots \mathrm{O}_{21}=2.561$ & $\mathrm{O}_{24}-\mathrm{H}_{24}=0.769(5)$ & $\mathrm{O}_{21} \ldots \mathrm{H}_{24}=1.801$ & $\mathrm{O}_{24}-\mathrm{H}_{24} \ldots \mathrm{O}_{21}=170$ \\
$\mathrm{O}_{1} \ldots \mathrm{O}_{22}=2.623$ & $\mathrm{O}_{1}-\mathrm{H}_{1}=0.739(3)$ & $\mathrm{O}_{22} \ldots \mathrm{H}_{1}=2.007$ & $\mathrm{O}_{1}-\mathrm{H}_{1} \ldots \mathrm{O}_{22}=141.10$ \\
$\mathrm{O}_{3} \ldots \mathrm{O}_{21}=2.601$ & $\mathrm{O}_{3}-\mathrm{H}_{3}=0.823(12)$ & $\mathrm{O}_{21} \ldots \mathrm{H}_{3}=1.786$ & $\mathrm{O}_{3}-\mathrm{H}_{3} \ldots \mathrm{O}_{21}=166.89$ \\
\hline
\end{tabular}

\subsection{Vibrational studies:}

In the present investigation, IR and Raman spectroscopic studies of $\mathrm{Tl}_{2} \mathrm{HAsO}_{4} \cdot \mathrm{Te}(\mathrm{OH})_{6}$ have been performed and analyzed in order to confirm the presence and the independence of the two anions ( $\mathrm{AsO}_{4}^{3-}$ and $\mathrm{TeO}_{6}^{6-}$ ). These two analyses give more importance to hydrogen bonds in the new crystal lattice. Raman and infrared spectra of $\mathrm{Tl}_{2} \mathrm{HAsO}_{4} \cdot \mathrm{Te}(\mathrm{OH})_{6}$, at room temperature, are shown in Figure 7 and Figure 8, respectively. The observed Raman and IR bands are given in Table 6.

\subsubsection{Interpretation of Raman spectrum:}

According to the literature of the addition compounds based on tellurate and materials stable due to the hydrogen bonds, we could interpret the different peaks observed in Figure 7.

In fact, the bands which appear at $60 \mathrm{~cm}^{-1}, 77 \mathrm{~cm}^{-1}$ and $96 \mathrm{~cm}^{-1}$ are attributed to the lattice mode. While the peaks at 153 , 184 and $234 \mathrm{~cm}^{-1}$ are probably assigned to hydrogen bonding $\mathrm{v}(\mathrm{O}-\mathrm{H} \ldots \mathrm{O})[3,15]$. 
The intense and narrow peak at $634 \mathrm{~cm}^{-1}$ is assigned to $\mathrm{v}_{1}\left(\mathrm{TeO}_{6}\right)$ [16], while in the others tellurates alkaline, this vibration mode appears at peak with frequency superior than $634 \mathrm{~cm}^{-1}$. Thus, in the $\mathrm{Rb}_{2} \mathrm{HAsO}_{4} \cdot \mathrm{Te}(\mathrm{OH})_{6}$, the $\mathrm{v}_{1}\left(\mathrm{TeO}_{6}\right)$ observed at $673 \mathrm{~cm}^{-1}$ [6]. The shoulder detected at $606 \mathrm{~cm}^{-1}$ is attributed to $\mathrm{v}_{2}\left(\mathrm{TeO}_{6}\right)[17,18]$. However, the peak at $396 \mathrm{~cm}^{-1}$ is assimilated to $\mathrm{v}_{4}\left(\mathrm{TeO}_{6}\right)$ [18]. In addition the peak detected at $375 \mathrm{~cm}^{-1}$ is attributed to $\mathrm{v}_{5}\left(\mathrm{TeO}_{6}\right)$ [17-19]. Whereas the band which appears at $290 \mathrm{~cm}^{-1}$ is attributed to $\mathrm{v}_{6}\left(\mathrm{TeO}_{6}\right)$ [16]. Vibrational analysis for the isolated $\mathrm{AsO}_{4}^{3-}$ anion with point group Td leads to four modes: $A 1\left(v_{1}\right), E\left(v_{2}\right), 2 F 2\left(v_{3}\right.$ and $\left.v_{4}\right)$. The $v_{1}$ mode is the totally symmetric stretching vibrational mode of the $\mathrm{AsO}_{4}^{3-}$ anion, $\mathrm{v}_{2}$ is the doubly degenerate bending mode, $\mathrm{v}_{3}$ and $\mathrm{v}_{4}$ are the triply degenerate stretching mode and bending mode respectively. In the free $\mathrm{AsO}_{4}^{3-}$ anion, they are found at $837,349,878$, and $463 \mathrm{~cm}^{-1}$, respectively. Based on this interpretation and examining the Raman spectra, we can note that $A_{1}$ band may shift to different wave numbers and the doubly degenerate $\mathrm{E}$ and triply degenerate $\mathrm{F}$ modes may give rise to several new $A 1, B 1$, and/or $E$ vibrations [20, 21]. In fact, we can assimilate the band which appears at $721 \mathrm{~cm}^{-1}$ to $\mathrm{v}_{1}\left(\mathrm{AsO}_{4}\right)$. While the three peaks observed at $797 \mathrm{~cm}$ $1,806 \mathrm{~cm}^{-1}$ and $823 \mathrm{~cm}^{-1}$ are relating to the triply degenerate bending and stretching mode $\mathrm{v}_{3}\left(\mathrm{AsO}_{4}\right)[20,21]$. The two regions (300-350) $\mathrm{cm}^{-1}$ and $(400-450) \mathrm{cm}^{-1}$ are assigned respectively to doubling degenerate bending mode $\mathrm{v}_{2}\left(\mathrm{AsO}_{4}\right)$ and $\mathrm{v}_{4}\left(\mathrm{AsO}_{4}\right)$ [22]. Thus, the peaks observed at $320 \mathrm{~cm}^{-1}$ and $341 \mathrm{~cm}^{-1}$ are attributed to $\mathrm{v}_{2}\left(\mathrm{AsO}_{4}\right)$. Whilst the band appears at $410 \mathrm{~cm}^{-1}$ is assimilated to $\mathrm{v}_{4}\left(\mathrm{AsO}_{4}\right)$.

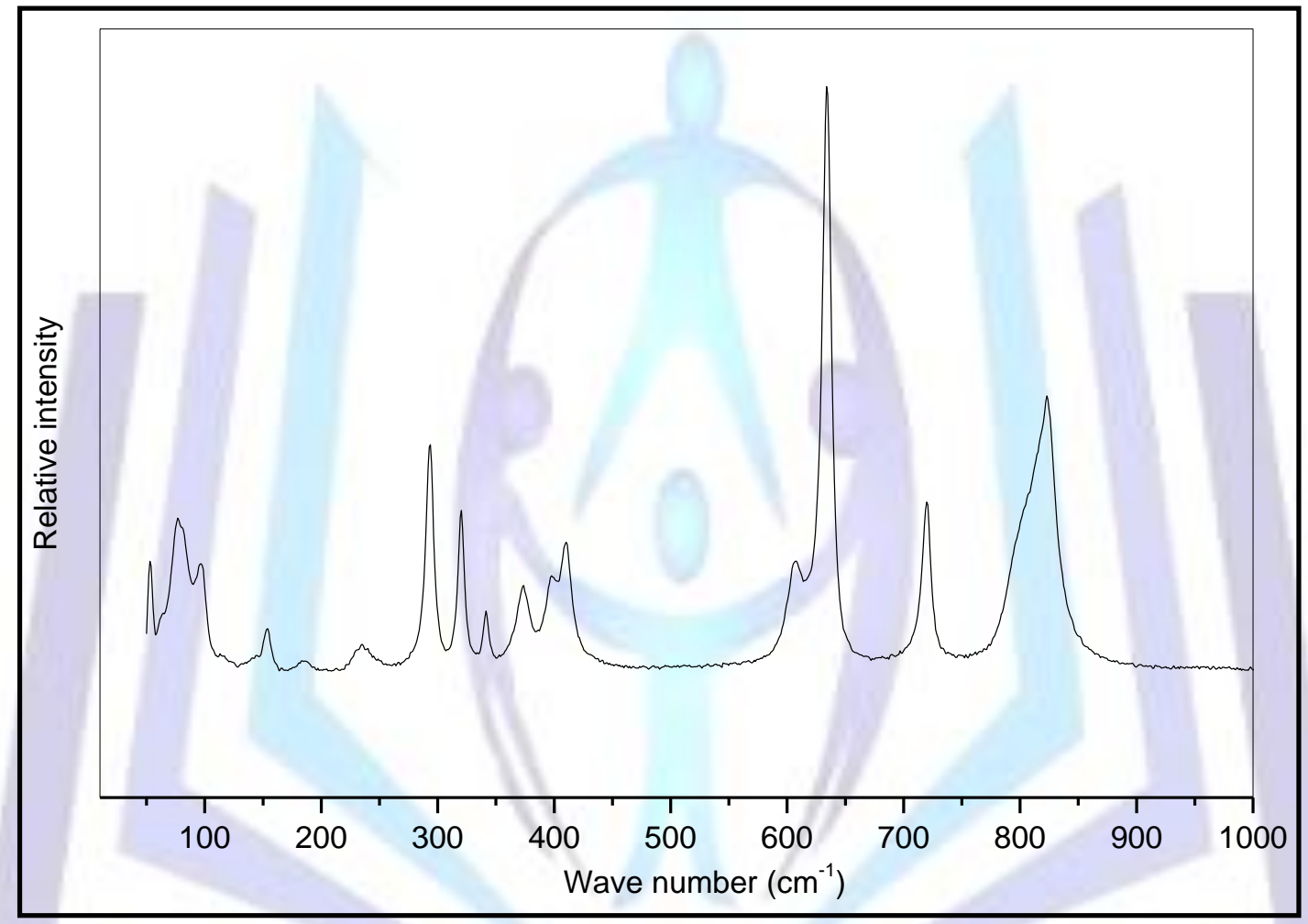

Fig 7: Raman spectra at room temperature of $\mathrm{Tl}_{2} \mathrm{HAsO}_{4} \cdot \mathrm{Te}(\mathrm{OH})_{6}$ compound.

\subsubsection{Interpretation of IR spectrum:}

In order to confirm the results got by the Raman spectra and to gain more information on the strong $\mathrm{O}-\mathrm{H}$...O hydrogen bond in this new structure ,we have undertaken the IR study, at room temperature ,in the frequency range (4000 -500) $\mathrm{cm}^{-1}$.

The band appeared at $634 \mathrm{~cm}^{-1}$ is attributed to $\mathrm{v}_{1}\left(\mathrm{TeO}_{6}\right)$ [16]. The peak detected at $1037 \mathrm{~cm}^{-1}$ is associated to the stretching bond $\delta(\mathrm{Te}-\mathrm{OH})[3,20]$.

In addition, the IR peak observed at $713 \mathrm{~cm}^{-1}$ is associated to the vibration mode $\mathrm{v}_{1} \mathrm{AsO}_{4}^{3-}$. Whilst the three peaks observed at $798 \mathrm{~cm}^{-1}, 857 \mathrm{~cm}^{-1}$ and $897 \mathrm{~cm}^{-1}$ are related to the vibration mode $\mathrm{V}_{3} \mathrm{AsO}_{4}^{3-}[20,21]$.

The $\delta\left(\right.$ As-O...H) bending vibration mode appears in the region between $1222 \mathrm{~cm}^{-1}$ and $1312 \mathrm{~cm}^{-1}[15,23,24]$. While the peaks detected at $1567 \mathrm{~cm}^{-1}$ and $1689 \mathrm{~cm}^{-1}$ are assigned to the presence of the As-O...H free and the presence of strong hydrogen bonds [25].

The peaks observed in the region being from 2300 to $2836 \mathrm{~cm}^{-1}$ may be assigned to the asymmetric and symmetric stretching vibrations of the O-H group of strong hydrogen bond [23, 26, 27]. 


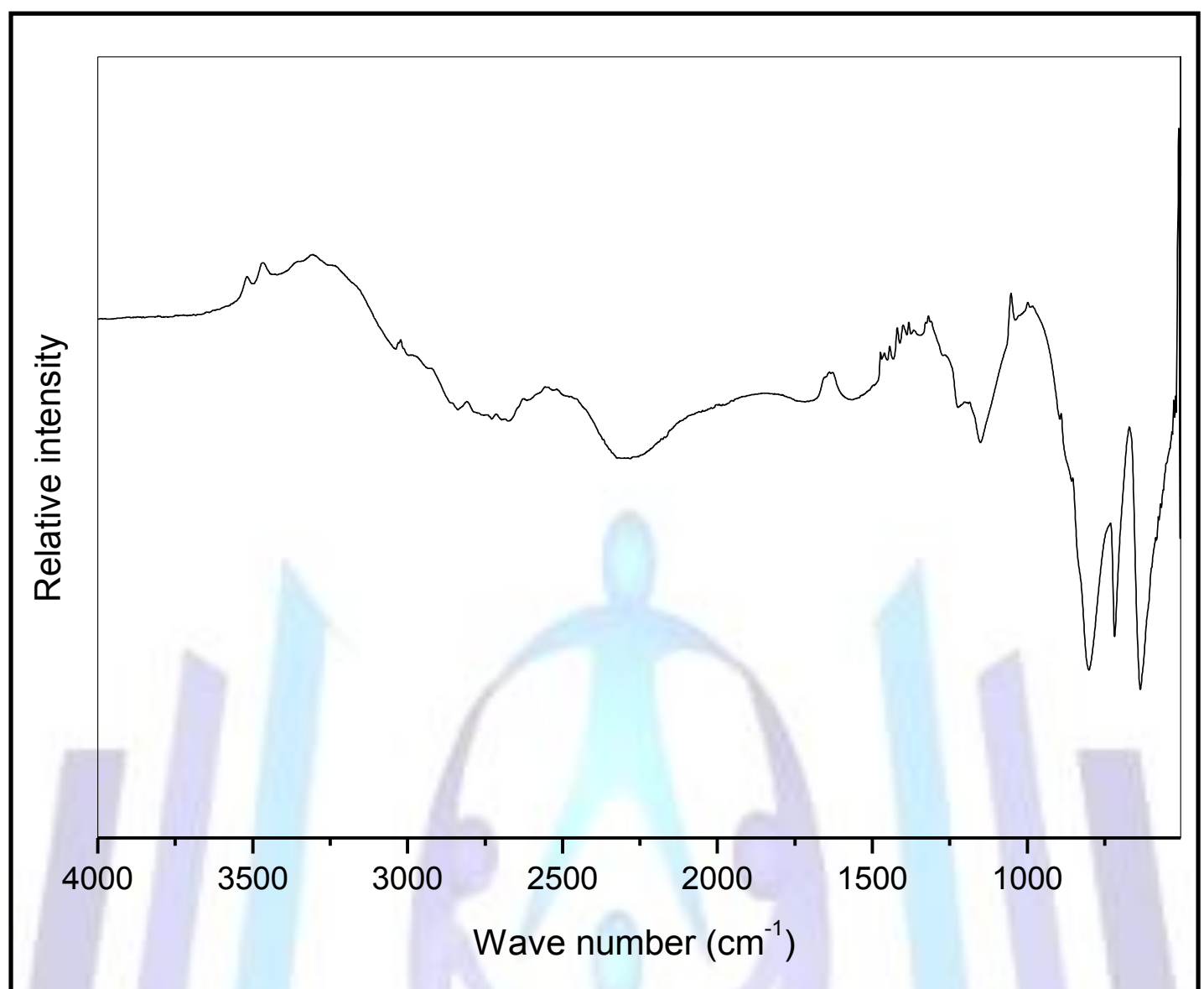

Fig 8: IR spectrum at room temperature of $\mathrm{Tl}_{2} \mathrm{HAsO}_{4} \cdot \mathrm{Te}(\mathrm{OH})_{6}$ compound.

Table 6. Infrared and Raman frequencies for $\mathrm{Tl}_{2} \mathrm{HAsO}_{4} \cdot \mathrm{Te}(\mathrm{OH})_{6}$ material.

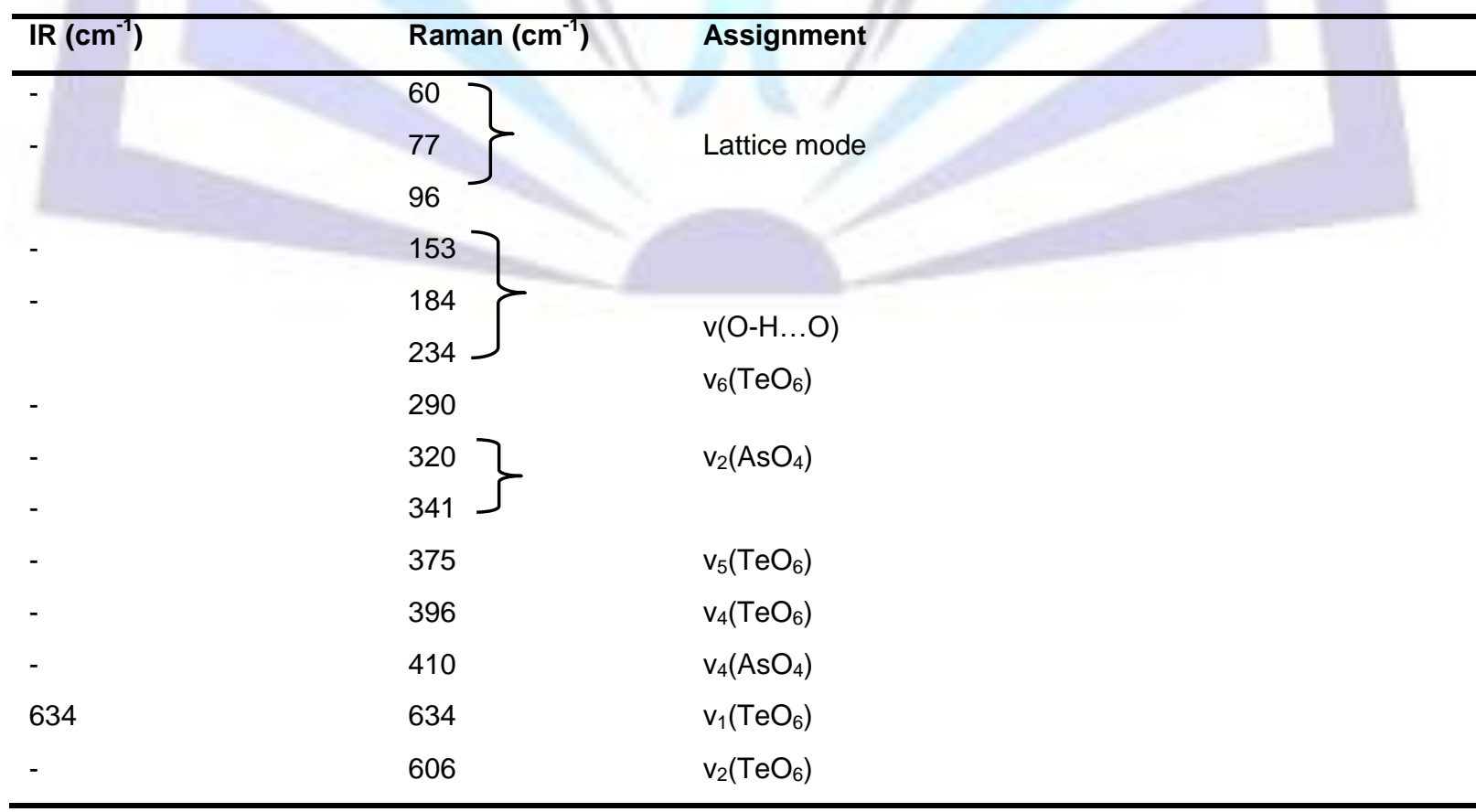




\begin{tabular}{|c|c|c|}
\hline 713 & 721 & $\mathrm{v}_{1}\left(\mathrm{AsO}_{4}\right)$ \\
\hline 798 & 797 & \\
\hline 857 & 806 & $\mathrm{~V}_{3}\left(\mathrm{AsO}_{4}\right)$ \\
\hline 897 & 823 & \\
\hline & & $\delta(\mathrm{Te}-\mathrm{OH})$ \\
\hline 1037 & & \\
\hline 1222 & & \\
\hline 1257 & & $\delta(\mathrm{Ac}=\mathrm{H})$ \\
\hline 1312 & & O(AS-U....T) \\
\hline 1567 & - & As-O... H free and the strong hydrogen bonds. \\
\hline 1689 & & \\
\hline 2300 & & \\
\hline 2670 & - & $\mathrm{v}(\mathrm{OH})$ \\
\hline 2800 & & \\
\hline
\end{tabular}

\section{MAGNETIC PROPERTIES.}

The crystals of $\mathrm{Tl}_{2} \mathrm{HAsO}_{4} \cdot \mathrm{Te}(\mathrm{OH})_{6}$ substances are massive enough to reach a magnetic response that could be higher than the signal detection for VSM option $\left(>10^{-6} \mathrm{emu}\right)$. Therefore, we have crushed the crystal with agate mortar and pestle in order to obtain a powder specimen. Flattened monocrystal had mounted on a quartz paddle-shaped sample holder and fixed with vacuum grease and PTFE tape. Powder materials had compressed inside a polypropylene powder holder that fit in a brass through-shaped sample holder. These materials have been supplied by Quantum Design Company [28]. Previously, the mass of all samples have been accurate determinate by a Sartorius balance (model CP225D).

Specific sequences have design in order to carry out the magnetic characterization at each composition: isothermal magnetization curves (for example, $\mathrm{M}(\mathrm{H}, \mathrm{T}=300 \mathrm{~K})$.seq), thermal variation of magnetization at fixed magnetic field (e.g., $\mathrm{M}(\mathrm{H}=1 \mathrm{kOe}, \mathrm{T})$.seq. For diamagnetic substance a single-valued function between both magnitudes is observed and at regular temperatures and magnetic fields is given by the linear relation: $\sigma=\chi_{m} H$.

\section{Diamagnetic substance: $\mathrm{Tl}_{2} \mathrm{HAsO}_{4} \cdot \mathrm{Te}(\mathrm{OH})_{6}$.}

A thorough study, as an example for a diamagnetic material, was carried out over the $\mathrm{Tl}_{2} \mathrm{AsO}_{4} \cdot \mathrm{Te}(\mathrm{OH})_{6}$ sample, where there is not a magnetic ion on its composition. It is worth noting that this sample have been mounted on paddle-shape sample holder which produces a lower level of noise in the measurement, will lead more accurate determination on magnetization (Table 7).

Table 7. Mass susceptibilities at $\mathrm{T}=300 \mathrm{~K}$ for $\mathrm{Tl}_{2} \mathrm{HAsO}_{4} \cdot \mathrm{Te}(\mathrm{OH})_{6}$ substance.

\begin{tabular}{rccc}
\hline Substance & $\boldsymbol{m}(\mathbf{k g})$ & $\boldsymbol{A}(\mathbf{u})$ & $\square \boldsymbol{m}\left(\mathbf{m}^{3} / \mathbf{k g}\right)$ \\
$\mathrm{Tl}_{2} \mathrm{HAsO}_{4} \cdot \mathrm{Te}(\mathrm{OH})_{6}$ & $1.215 \times 10^{-5}$ & 777.30 & $-6.892(8) \times 10^{-9}$ \\
\hline
\end{tabular}

The Figure 9 shows the variation of $\chi_{m}$ with temperature derived from temperature-dependence of $\sigma$ at applied magnetic field of $\mu_{0} H=14 \mathrm{~T}$. A remarkable peak is observed around $50 \mathrm{~K}$ that can ascribe to oxygen trapped by the Teflon tape used to wrap the sample [29]. 


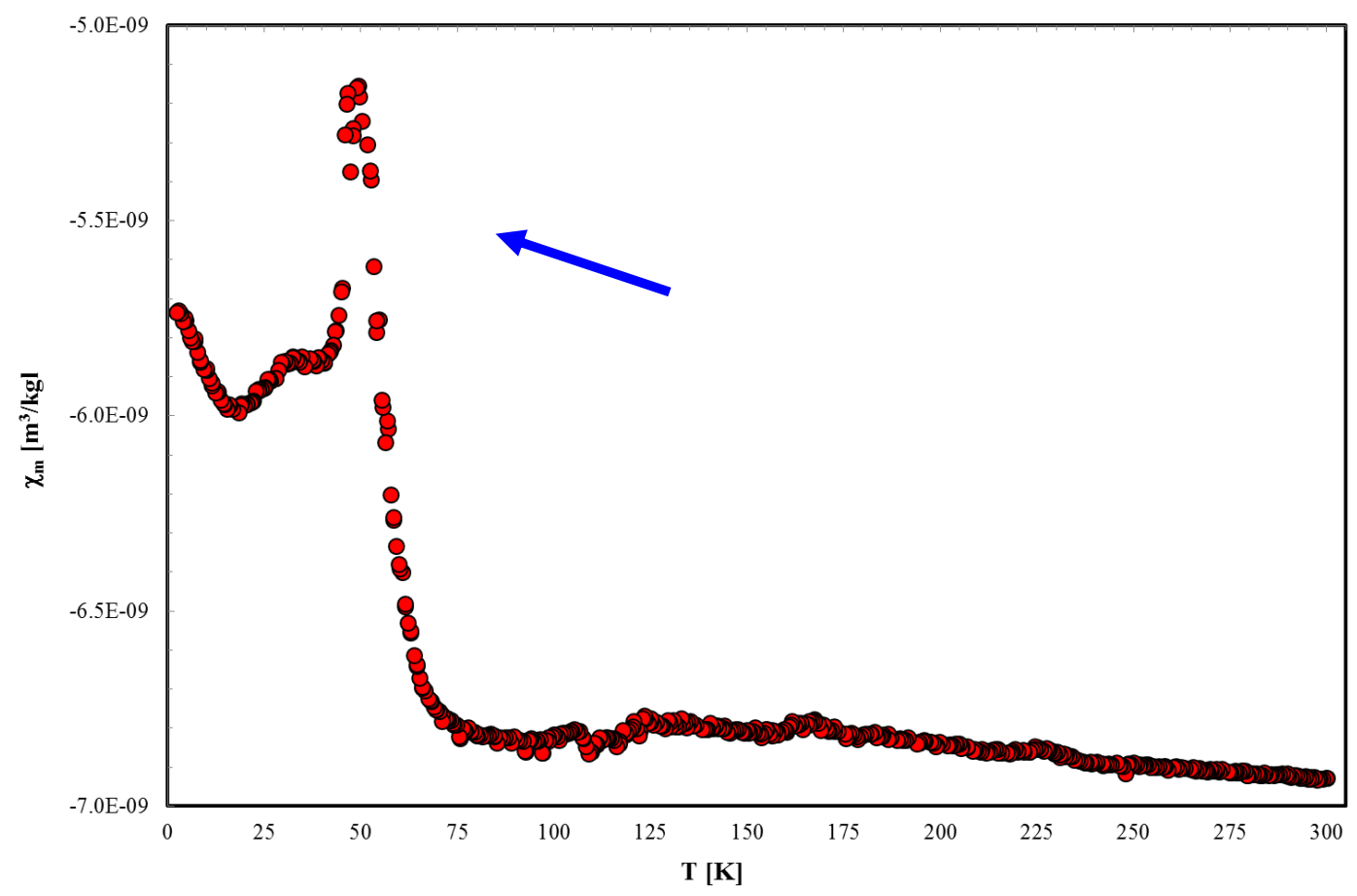

Fig 9: Temperature-dependence of the mass susceptibility, $\chi_{m}$, for $\mathrm{Tl}_{2} \mathrm{HAsO}_{4} \cdot \mathrm{Te}(\mathrm{OH})_{6}$ substance. The blue arrow points out the paramagnetic contamination due to oxygen migrated from PTFE tape.

In this way, above this temperature $\chi_{m}$ is almost constant; whereas below it, paramagnetic oxygen contamination produces a slight increase on the value of $\chi_{m}$ measured. Paramagnetic contribution, from oxygen migrating from the PTFE tape, is even clearly visible if an observer compares the isothermal magnetization curves at 300 and $2 \mathrm{~K}$ (Figure 10). The difference between both curves has roughly the shape of a Brillouin function, which is a feature of paramagnetic substances at low temperature and/or high applied magnetic field and which should be produced by the presence of the paramagnetic oxygen.

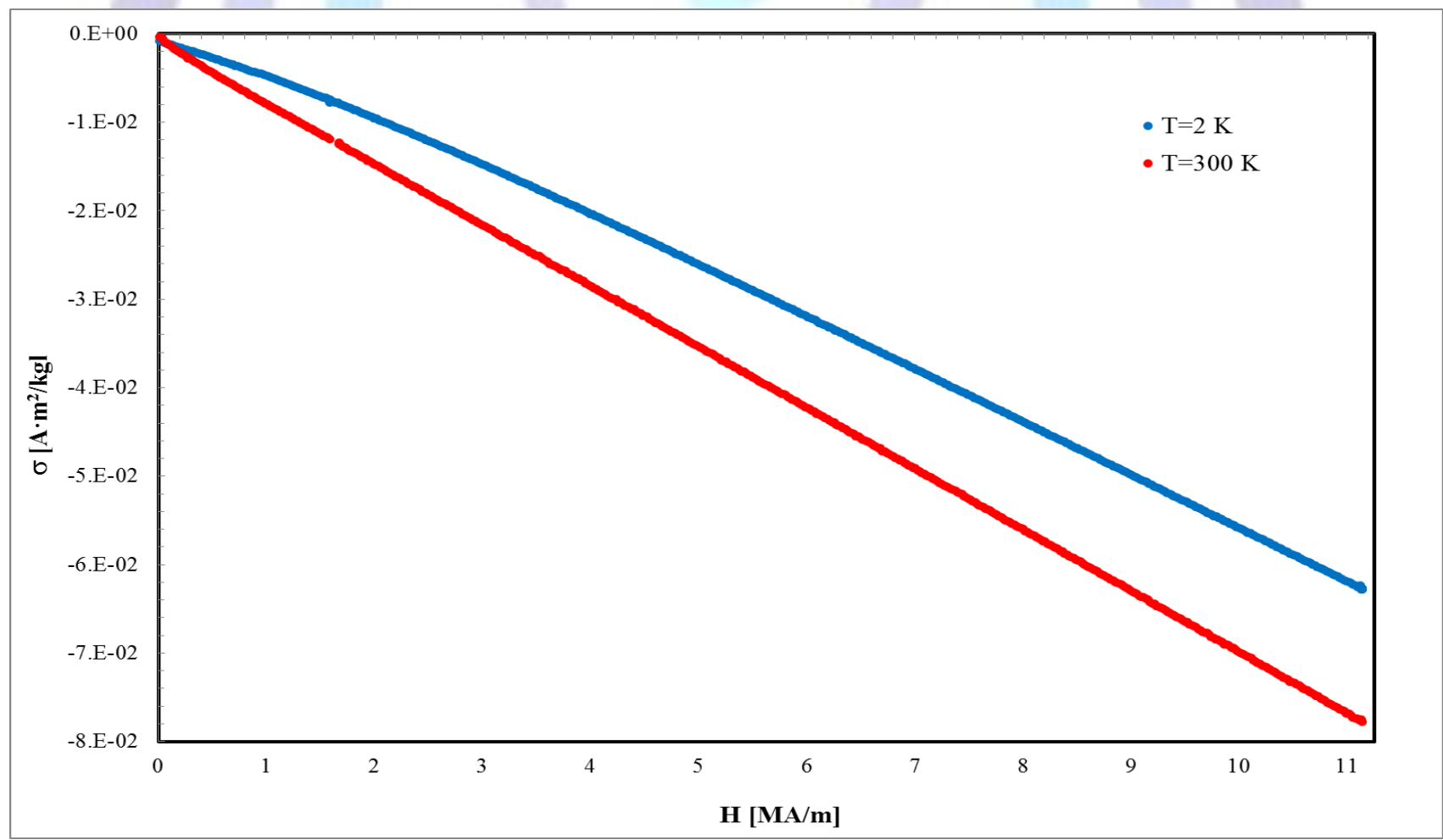

Fig 10: Isothermal magnetic curves of $\mathrm{Tl}_{2} \mathrm{HAsO}_{4} \cdot \mathrm{Te}(\mathrm{OH})_{6}$ substance measured at 2 y $300 \mathrm{~K}$. 


\section{CONCLUSION:}

In the present work, the single crystal of the compound $\mathrm{Tl}_{2} \mathrm{HAsO}_{4} \cdot \mathrm{Te}(\mathrm{OH})_{6}$ synthesized by slow evaporation, at room temperature, has been studied. It crystallizes in the triclinic system PT.

The cohesion of this structure is assured by the strong hydrogen bond and the electrostatic actions of the $\mathrm{TI}^{+}$cations. The Raman study shows that the bending and stretching mode $\mathrm{v}_{3}\left(\mathrm{AsO}_{4}\right)$ is triply degenerate while the bending mode $\mathrm{v}_{2}\left(\mathrm{AsO} \mathrm{O}_{4}\right)$ is doubly degenerate. The magnetic characterization of the thallium hydrogen arsenate tellurate shows that the (TIAsTe) behaves as diamagnetic material.

\section{ACKNOWLEDGMENTS}

This work is supported by the minister of Higher Education and Research of Tunisia. All the authors would like to express their thanks to Dr. H. Khemakhem for his help in the spectroscopies Raman measurements.

\section{REFERENCES:}

[1] Litaiem, H., Dammak, M., Mhiri, T., and Cousson, A. J. Alloys Comp, 396 (2005) 34.

[2] Dammak, M., Litaiem, H., and Mhiri, T. J. Alloys Comp, 416 (2006) 228.

[3] Dammak, M., Khemekhem, H., Mhiri, T., Kolsi, A.W., and Daoud, A. J. Alloys Comp, 280 (1998) 107.

[4] Dammak, M., Khemakhem,H., and Mhiri, T. J. Phys. Chem. Solids, 62 (2001) 2069.

[5] Khemakhem,H. Ferroelectric 234 (1999) 47.

[6] Bechibani, I., Litaiem, H., Ktari, L., Lhoste, J., and Dammak, M. J. Mol. Struct, 1045 (2013) 199.

[7] Palatinus, L., and Chapuis, G. SUPERFLIP, program for the solution of crystal structures, J.of Appl. Cryst., 40 (2007) 786.

[8] Sheldrick, G. M. SHELXL 97, program for the solution of crystal structures, univ. of GÖttingen (Germany) (1997).

[9] Brandenburg, K., and Berndt, M. DIAMOND, Version 2.1.b, Crystal impact Gb R Bonn, Germany (1999).

[10] Ktari, L., Abdelhedi, M., Bouhlel, N., Dammak, M., and Cousson, A. J. Mater. Res. Bull. 44 (2009) 1792.

[11] Mullica, D. F., Korp, J. D., Milligan, W. O., Beall, G. W., and Bernal, I. Acta Crystallogr., B36 (1980) 2565.

[12] Zilber, R., Durif, A., and Averbouch-Pouchet, M.T. Acta Cystallogr., B38 (1982) 1554.

[13] Lee, C., and Harrison, W. T. A. J. Acta Crystallogr., C 63 (2007) 308.

[14] Brown, L. D. J. of Acta Crystallogr., A 32 (1976) 24.

[15] Naili, H., Mhiri, T., and Jaud, J. J. Solid State Chem, 16 (2001) 161.

[16] Ktari, L., Dammak, M., Hadrich, A., Cousson, A., Nierlich, M., Romain F., and Mhiri, T. J. Solid State Sci 6 (2004) 1393.

[17] Dammak, M., Khemakhem, H., Mhiri, T., Kolsi, A.W., and Daoud, A. J. Solid State Chem, 145 (1999) 612.

[18] Litaiem, H., Dammak, M., Ktari, L., Kammoun, S., and Mhiri, T. J. Phase transitions vol 77, N 11 (2004) 929.

[19] Chabchoub, N., Khemakhem, H., and Von der mühll, R. J. Alloys Comp, 386 (2005) 319.

[20] Frost, R. L., Sejkora, C. J., Plasil, J., Reddy, B. J., and Keeffe, E. C. Spectrochimica Acta Part A 78 (2011) 494.

[21] Jrifi, A., El Jazouli, A., Chaminade, J. P., and Couzi, M. Powder Diffraction 24, 3 (2009) 200.

[22] Frost, R. L. Spectra Chimica Acta., A71 (2009) 1788.

[23] Amri, M., Zouari, N., Mhiri,T., and Gravereau, P. J. Alloys Comp, 477 (2009) 68.

[24] Amri, M., Zouari, N., Mhiri,T., Pechev, S., Gravereau, P., and Von Der Muhll, R. J. Phys.Chem. Solids, 68 (2007) 1281.

[25] Bortun, A. I., Bortun, L. N., Clear field Trobajo, A. C., and Garcia, J. R. J. Mater.Res. Bull, Vol 33,4 (1998) 583.

[26] Hadrich, A., Lautie, A., and Mhiri, T. J. Raman Spectroscopy, 31 (2000) 587.

[27] Hadzi, D., and Bratos, S. The hydrogen bond, recent development in theory an experiments, North Hallond, Amsterdam ,Tome 2 (1977) 588.

[28] VSM sample mounting techniques, Quantum Dessign Application Note 1096-306.

[29] Ard W.B., Shields H., and Gordy W., J. Chem. Phys, 23 (1955) 1727.

[30] Fabry, J., Loub, J., and Feltl, L. J. Thermal Analysis, 24 (1982) 95. 